\title{
BMJ Open Measuring physician practice, preparedness and preferences for genomic medicine: a national survey
}

\author{
Amy Nisselle (1) ,1,2 Emily A King, ${ }^{1,2}$ Belinda McClaren, ${ }^{1,2}$ Monika Janinski, ${ }^{1}$ \\ Sylvia Metcalfe, ${ }^{1,2}$ Clara Gaff, ${ }^{1,2}$ Australian Genomics Workforce \& Education \\ Working Group
}

To cite: Nisselle A, King EA, McClaren B, et al. Measuring physician practice, preparedness and preferences for genomic medicine: a national survey. BMJ Open 2021;11:e044408. doi:10.1136/ bmjopen-2020-044408

- Prepublication history and supplemental material for this paper is available online. To view these files, please visit the journal online (http://dx.doi. org/10.1136/bmjopen-2020044408).

AN and EAK are joint first authors.

Received 03 September 2020 Accepted 27 May 2021

Check for updates

(c) Author(s) (or their employer(s)) 2021. Re-use permitted under CC BY-NC. No commercial re-use. See rights and permissions. Published by BMJ.

${ }^{1}$ Australian Genomics, Genomics in Society, Murdoch Children's Research Institute, Parkville, Victoria, Australia

${ }^{2}$ Department of Paediatrics, The University of Melbourne Faculty of Medicine Dentistry and Health Sciences, Parkville, Victoria, Australia

Correspondence to

Professor Clara Gaff;

cgaff@unimelb.edu.au

\section{ABSTRACT}

Objective Even as genomic medicine is implemented globally, there remains a lack of rigorous, national assessments of physicians' current genomic practice and continuing genomics education needs. The aim of this study was to address this gap.

Design A cross-sectional survey, informed by qualitative data and behaviour change theory, to assess the current landscape of Australian physicians' genomic medicine practice, perceptions of proximity and individual preparedness, and preferred models of practice and continuing education. The survey was advertised nationally through 10 medical colleges, 24 societies, 62 hospitals, social media, professional networks and snowballing. Results 409 medical specialists across Australia responded, representing 30 specialties (majority paediatricians, $20 \%)$, from mainly public hospitals (70\%) in metropolitan areas $(75 \%)$. Half $(53 \%)$ had contacted their local genetics services and half $(54 \%)$ had ordered or referred for a gene panel or exome/genome sequencing test in the last year. Two-thirds (67\%) think genomics will soon impact their practice, with a significant preference for models that involved genetics services $(p<0.0001)$. Currently, respondents mainly perform tasks associated with pretest family history taking and counselling, but more respondents expect to perform tasks at all stages of testing in the future, including tasks related to the test itself, and reporting results. While one-third (34\%) recently completed education in genomics, only a quarter (25\%) felt prepared to practise. Specialists would like (more) education, particularly on genomic technologies and clinical utility, and prefer this to be through varied educational strategies.

Conclusions This survey provides data from a breadth of physician specialties that can inform models of genetic service delivery and genomics education. The findings support education providers designing and delivering education that best meet learner needs to build a competent, genomic-literate workforce. Further analyses are underway to characterise early adopters of genomic medicine to inform strategies to increase engagement.

\section{INTRODUCTION}

Genomic sequencing is shifting from the realm of research to healthcare. ${ }^{1}$ A recent review identified five models for the provision

\section{Strengths and limitations of this study}

- The survey tool is based in behaviour change theory and developed from empirical data to capture patterns of genomic practice and preferences, allowing comparisons across different settings and change over time.

- We employed an extensive, multistaged and overlapping recruitment strategy at a national level to reach as many Australian medical specialists and trainees as possible.

- We successfully gathered data from over 30 specialties, the broadest sample reported in the literature to date.

- Our sample is still relatively small, and overrepresented for older specialists and those working in rural and remote areas, which may influence the findings.

- Our study is the first to investigate the genomics education and training needs and preferences of a national sample of a broad range of medical specialties.

of genetic testing globally, including genetics services led by geneticists, referral by primary care physicians to genetics services, and medical specialist-led testing. ${ }^{2}$ The shortage of a specialist genetic workforce suggests that medical specialist-led testing will be necessary. ${ }^{34}$ A scoping review of genetic specialist workforces internationally emphasised the need for a medical specialist-led model, noting education as a driver of workforce capacity. ${ }^{5}$

A national alliance of over 80 partner organisations, Australian Genomics, formed in 2016 to conduct research supporting adoption of genomics into Australian healthcare. ${ }^{6}$ At that time, microarray analysis and a limited number of single gene tests were reimbursed through the federally funded Medicare Benefit Scheme (MBS). Genomic sequencing tests were largely available through research studies or patient funding until 2020, when 
exome/genome sequencing (E/GS) for certain conditions was included on the MBS. ${ }^{7}$

Despite national initiatives driving the use of germline genomic tests by medical specialists not qualified in genetics, there are indications that physicians may prefer to refer to genetics services. ${ }^{89}$ Cumulative evidence indicates a lack of physician confidence in genomic medicine and low rates of clinical adoption of genomic testing. ${ }^{10}$ Studies investigating practice and preparedness span specialties and countries: Dutch cardiologists, ${ }^{11}$ European obstetricians and paediatricians, ${ }^{12}$ Wisconsin physicians, ${ }^{13}$ British gastroenterologists, ${ }^{14}$ Australian intensivists ${ }^{8}$ and neurologists worldwide. ${ }^{15}$ However, there are no national studies surveying a range of specialties.

Education strategies have been proposed or implemented to support medical professionals' genomic medicine knowledge and skills. ${ }^{16} 17$ Following medical school training, ${ }^{1819}$ continuing professional development (CPD), whether accredited or not, aims to supplement knowledge and skills for those already in practice. ${ }^{2021}$ To inform Australian national strategy and local development of genomics CPD, a needs assessment inclusive of a multiple specialties across diverse contexts is required. We previously reported development of a survey underpinned by qualitative data and an empirically derived framework of behaviour change in which capability, opportunity and motivation influence, and are influenced by, behaviour (the COM-B model). ${ }^{22}$

Here, we describe comprehensive deployment of this survey nationally to multiple medical specialties. We present a snapshot of the current landscape of Australian specialists' genomic medicine practice, perceptions of proximity of genomic medicine and individual preparedness, and preferred models of practice and continuing education.

\section{METHODS}

In Australia, after obtaining a medical degree, doctors undertake specialty training. ${ }^{23}$ This typically involves completing 3 years of basic training ('Basic Trainee'), followed by 3 years of advanced training ('Advanced Trainee'). Medical colleges provide the training relevant to the medical specialty, for example, the Royal Australasian College of Surgeons trains surgeons, the Royal Australasian College of Physicians trains physicians, etc. Exposure to genetics/genomics varies across training programmes. After successful completion of final college examinations, they become a fellow of the relevant medical college. Recognising that the term 'physician' has different meanings in different countries, here we define 'physicians' as doctors whose primary affiliation is with the Royal Australasian College of Physicians . Medical professionals may work in public hospitals, which are the responsibility of state governments and/or privately. Patients receive some reimbursement for private consultations and specified pathology tests through the Federal Government's MBS. At the time of the survey, there were
20 genetics conditions for which tests were reimbursed through the MBS (see online supplemental table S1). Clinical genetics services provide screening, diagnostic and genetic counselling services to patients on referral by a medical practitioner. They are based primarily in publicly-funded hospitals and staffed by health professionals trained in genetics (eg, clinical geneticists, genetic counsellors). Here, we focus on the non-genetic medical workforce and as such define 'medical specialists' as medical doctors who are trained or in training for a specialty other than clinical genetics. We excluded general practitioners (family physicians) who practise general medicine in the community and genetic specialists (eg, clinical geneticists and genetic counsellors) as separate studies were conducted for those subspecialties. ${ }^{4}$ (Cusack et al, Australian Journal of General Practice, in press). We also excluded radiologists and pathologists as in Australia they typically perform investigations rather than requesting genomic tests and oncologists, as they are the focus of other ongoing national studies.

Details of survey development, domains and the full set of questions have been reported elsewhere. ${ }^{20} 24$ In brief, the survey is informed by the COM-B model and includes 28 questions across five key domains: personal characteristics, current practice with genomic medicine, perception of preparedness to practice genomic medicine, perception of how proximal genomic medicine is to clinical practice and preferences for future models of practice and education. We defined 'genomic medicine' as the use of testing that investigates many regions of the genome at once, such as gene panels and E/GS, but excluding non-invasive prenatal testing using sequencing technologies. The scope of the survey was testing to investigate genetic conditions. The survey was deployed electronically from February to September 2019 using Research Electronic Data Capture software hosted at the Murdoch Children's Research Institute. ${ }^{25}$

Respondents provided consent by completing the initial screening and consent question.

\section{Recruitment}

Inclusion criteria

Medical specialists were eligible to complete the survey if they had commenced or completed their specialist training and were currently practising clinically in Australia.

\section{Recruitment was staged through}

- Relevant medical colleges (March-June 2019) and societies/associations (April-June 2019)

- Hospitals (June-October 2019). One hundred and thirty-two hospitals were identified from the 'MyHospitals' search tool on the Australian Institute of Health and Welfare website ${ }^{26}$ to represent both public and private hospitals in metropolitan, regional and rural settings across all Australian states.

- Social media (June-July 2019). Three tweets were posted on the Australian Genomics Twitter account (https://twitter.com/AusGenomics) over 10 business 
days, then this process was repeated twice, with approximately 1 week between each cluster of tweets. Content referenced specific survey questions or preliminary data to pique interest of potential participants. For example, Early survey results suggest that even though medical specialists are ordering \#genomictests for their \#patients, many don't feel \#prepared for \#genomicmedicine. We want to know how you feel (LINK)' or 'Do you feel ready for \#genomics in \#clinicalpractice? We want to hear from Australian medical specialists (LINK)'.

- Investigator networks of national and state-based genomics initiatives, Australian Genomics and Melbourne Genomics (July 2019).

Medical colleges, societies and hospitals circulated information about the study to their membership or staff using regular communication channels, for example, newsletters, e-bulletins, emails, etc. Information was circulated up to three times per organisation, dependent on advertising charges, perceived responder burden and/or internal timelines. The information included a brief description of the study, ethics approval and a link to access the online survey. Recruitment also included professional networks and snowball sampling throughout, with all contacts asked to retweet Australian Genomics tweets if possible. All respondents were asked to share the survey with relevant colleagues.

\section{Data cleaning and analysis}

Data were exported to, cleaned and then analysed in Stata 16.0. Cleaning involved removing surveys completed by ineligible respondents or surveys with no data beyond demographic questions. For analysis, career stage was grouped into Basic Trainee, Advanced Trainee or Fellow, as defined above. Specialists were grouped according to self-reported primary college affiliation. All categorical questions included an open-ended text option for 'Other'; qualitative data provided for these questions were reviewed by three researchers (AN, EAK and MJ) and recoded into existing response categories if possible (see online supplemental table S2). Representative quotes are provided in (online supplemental table S3) for illustrative purposes where they enhance the understanding of the quantitative results.

Descriptive and inferential statistics were used to analyse the data, including two-sample tests of proportions, $\chi^{2}$ or Fisher's exact tests as appropriate to data characteristics. A $p<0.05$ was considered significant. When determining representativeness of the sample, data were referenced against Medical Board of Australia Registrant data, ${ }^{27}$ the National Medical Training Advisory Network ${ }^{28} 29$ and the National Health Workforce Dataset. ${ }^{30}$

\section{RESULTS}

\section{Recruitment and response rates}

As shown in figure 1, recruitment strategies were staggered and overlapping from March to October 2019.

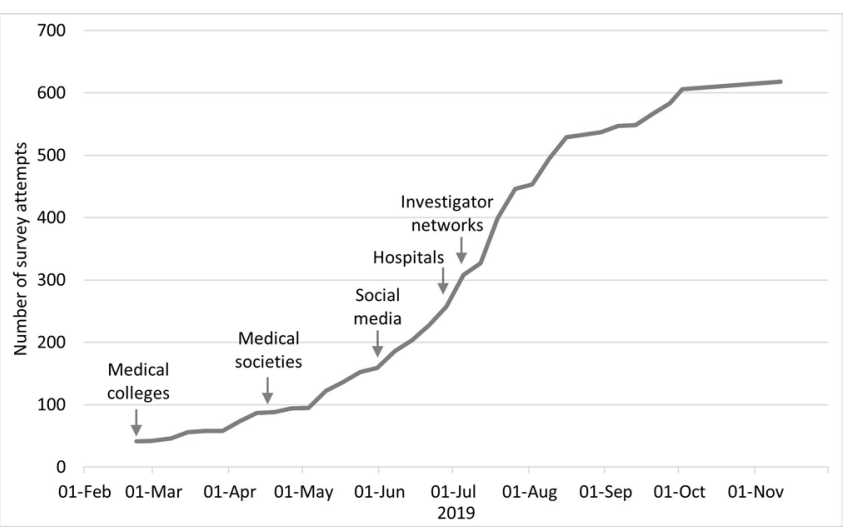

Figure 1 Number of survey attempts shown with recruitment strategies and timelines after pilot data were complete $(n=41)$. Recruitment start dates are shown and overlapped from March to October 2019 (as described in the methods). Snowball recruitment may have continued beyond these periods (eg, forwarding a newsletter or retweeting) but this could not be monitored.

All 10 Australian medical colleges and 24 of 55 medical societies/associations approached agreed to advertise the survey. Of 132 health networks (functional or geographical groups of Australian public hospitals defined by the relevant State Government) and hospitals contacted, ${ }^{31}$ 62 agreed to advertise the survey (67.6\% of metropolitan hospitals and $42.9 \%$ of remote hospitals), which was subsequently shared with staff at a total of 74 hospitals. There were an estimated 37000 trainees and fellows in our target specialty audiences at the time of the survey. ${ }^{27}$ However, using diverse recruitment approaches that could target one individual in several ways and at several time points meant that it was not possible to determine how many medical specialists were aware of the survey during the recruitment period.

\section{Sample characteristics and representativeness}

Of 617 attempts at survey responses, 54 did not meet the inclusion criteria and 154 did not complete any questions beyond consent to participate (see online supplemental figure S1). A total of 409 responses were therefore included in analyses. Totals differ across questions due to opportunity to provide more than one response, missing data or attrition; where this has occurred, the denominator has been described.

Table 1 presents respondent demographics compared with reference data from the Medical Board of Australia, ${ }^{27}$ the National Medical Training Advisory Network ${ }^{28}{ }^{29}$ and the National Health Workforce Dataset. ${ }^{30}$ Our sample had slightly less males $(\mathrm{p}=0.039)$, was under-represented for 25-34 year olds $(p<0.0001)$, and over-represented for $55-64$ year olds $(\mathrm{p}<0.0001)$. As would be expected from this age bias, there was a smaller proportion of Basic and Advanced Trainees than expected from the reference data and a larger proportion of Fellows $(\mathrm{p}<0.0001)$. Our sample was broadly representative of primary work locations of medical specialists across Australia. Of the eight Australian states and territories, one was over-represented 
Table 1 Description of the sample and representativeness $(n=409)$

\begin{tabular}{|c|c|c|c|c|c|}
\hline \multirow[b]{2}{*}{ Characteristic } & \multicolumn{2}{|c|}{ Respondents } & \multicolumn{2}{|c|}{ Reference data } & \multirow[b]{2}{*}{$P$ value } \\
\hline & n (\%) & $95 \% \mathrm{Cl}$ & $\mathbf{N}(\%)$ & $95 \% \mathrm{Cl}$ & \\
\hline \multicolumn{6}{|l|}{ Gender* } \\
\hline Male & $213(52.1)$ & 47.2 to 56.9 & $61700(57.1)$ & 56.8 to 57.4 & 0.039 \\
\hline Female & $185(45.2)$ & 40.4 to 50.1 & $46281(42.9)$ & 42.6 to 43.2 & 0.33 \\
\hline Prefer not to answer & $11(2.7)$ & 1.5 to 4.8 & - & - & - \\
\hline \multicolumn{6}{|l|}{$\mathrm{Age}^{*}$} \\
\hline$\leq 24$ years & - & - & $398(0.4)$ & - & \\
\hline 25-34 years & $29(7.1)$ & 4.6 to 9.6 & $26827(24.8)$ & 24.6 to 25.1 & $<0.0001$ \\
\hline $35-44$ years & $114(27.9)$ & 23.5 to 32.2 & $28431(26.3)$ & 26.1 to 26.6 & 0.4794 \\
\hline $45-54$ years & $123(30.1)$ & 25.6 to 34.7 & $22415(20.8)$ & 20.5 to 21.0 & $<0.0001$ \\
\hline $55-64$ years & $103(25.2)$ & 21.2 to 29.6 & $18060(16.7)$ & 16.5 to 17.0 & $<0.0001$ \\
\hline$\geq 65$ years & $40(9.8)$ & 7.2 to 13.1 & $11852(11.0)$ & 10.8 to 11.2 & 0.4398 \\
\hline \multicolumn{6}{|l|}{ Trainee level† } \\
\hline Basic trainee & $9(2.2)$ & 1.3 to 4.6 & $5858(12.1)$ & 11.8 to 12.4 & $<0.0001$ \\
\hline Advanced trainee & $18(4.4)$ & 2.6 to 6.7 & 8890 (18.3) & 18.0 to 18.7 & $<0.0001$ \\
\hline Fellow & $382(93.4)$ & 89.9 to 95.0 & 33749 (69.6) & 69.2 to 70.0 & $<0.0001$ \\
\hline \multicolumn{6}{|l|}{ Australian state or territory ${ }^{\star} \ddagger$} \\
\hline Australian Capital Territory & $28(6.9)$ & 4.4 to 9.3 & $702(1.9)$ & 1.8 to 2.0 & $<0.0001$ \\
\hline New South Wales & $119(29.1)$ & 24.7 to 33.5 & $11566(31.2)$ & 30.7 to 31.7 & 0.3622 \\
\hline Northern Territory & $8(2.0)$ & 0.6 to 3.3 & $373(1.0)$ & 0.9 to 1.1 & 0.0568 \\
\hline Queensland & $75(18.3)$ & 14.8 to 22.4 & $7320(19.7)$ & 19.3 to 20.1 & 0.4777 \\
\hline South Australia & $20(4.9)$ & 2.8 to 7.0 & $2896(7.8)$ & 7.5 to 8.1 & 0.0283 \\
\hline Tasmania & $13(3.2)$ & 1.5 to 4.9 & $759(2.0)$ & 1.9 to 2.2 & 0.1091 \\
\hline Victoria & $119(29.1)$ & 24.7 to 33.5 & $9,952(26.8)$ & 26.4 to 27.3 & 0.3063 \\
\hline Western Australia & $26(6.4)$ & 4.0 to 8.7 & $3510(9.5)$ & 9.2 to 9.8 & 0.0324 \\
\hline \multicolumn{6}{|l|}{ Primary work location $\ddagger \S$} \\
\hline Major city & $306(75.0)$ & 70.6 to 79.0 & 72304 (79.2) & 78.9 to 79.4 & 0.0391 \\
\hline Inner regional & $59(14.5)$ & 11.4 to 18.2 & $12422(13.6)$ & 13.4 to 13.8 & 0.6127 \\
\hline Outer regional & $31(7.6)$ & 5.4 to 10.6 & $5299(5.8)$ & 5.7 to 6.0 & 0.1216 \\
\hline Remote & $10(2.5)$ & 1.3 to 4.5 & $865(1.0)$ & 0.9 to 1.0 & 0.0018 \\
\hline Very remote & $2(0.5)$ & 0.1 to 2.0 & $376(0.4)$ & 0.4 to 0.5 & 0.8048 \\
\hline \multicolumn{6}{|l|}{ Primary employerף } \\
\hline Public hospital or healthcare provider & $288(70.4)$ & 65.8 to 74.7 & & & \\
\hline Private hospital or healthcare provider & $17(4.2)$ & 2.6 to 6.6 & & & \\
\hline Self-employed/ private practice & $83(20.3)$ & 16.7 to 24.5 & & & \\
\hline $\begin{array}{l}\text { Other (government, research institute, } \\
\text { etc) }\end{array}$ & $21(5.1)$ & 3.4 to 7.8 & & & \\
\hline
\end{tabular}

*Reference data: Registration Data Table 2019. ${ }^{27}$

†Reference data: Medical Education and Training in Australia. ${ }^{29}$ $\ddagger \mathrm{n}=408$ for state and location.

§Reference data: Medical Workforce Factsheet 2016. ${ }^{30}$

ๆ There were no comparable reference data for this category.

(Australian Capital Territory; $\mathrm{p}<0.0001$ ) and two were under-represented (South Australia; $\mathrm{p}=0.028$ ); Western Australia; $\mathrm{p}=0.032$ ). Although three-quarters of respondents worked in a major city, those working in remote regions were significantly over-represented in our sample $(\mathrm{p}=0.0018)$. The majority of respondents were primarily employed at public hospitals or healthcare providers. A quarter of respondents had been involved in a genomics 


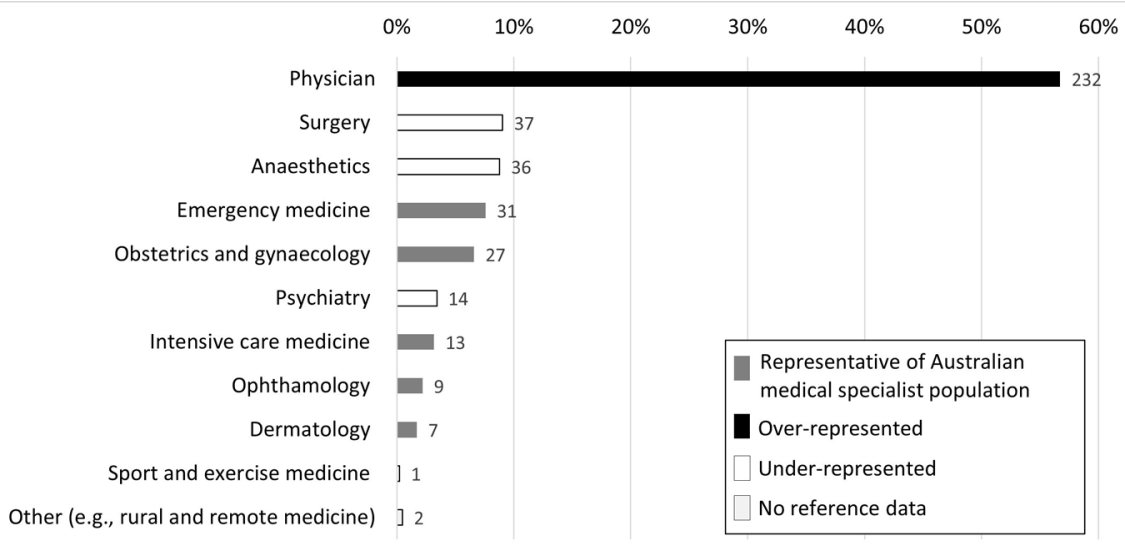

Figure 2 Proportion of each reported primary specialty in the sample $(n=409)$ grouped by primary medical college affiliation. Grey bars signify specialties where proportions were representative of the medical specialist population when compared with reference data. ${ }^{27}$ The black bar signifies a specialty which was over-represented (physicians; $\left.p<0.0001\right)$. White bars signify specialties which were under-represented: anaesthesiology $(p=0.002)$, psychiatry $(p<0.0001)$ and surgery $(p<0.0001)$. The reference data did not include a classification for 'rural and remote medicine', so representativeness could not be determined for this specialty (pale grey bar).

research project in the last 5 years $(\mathrm{n}=96,24.7 \%)$. Of these, respondents were involved in clinical $(83.3 \%)$, laboratory $(49.0 \%)$, bioinformatics $(15.6 \%)$ and/or social science $(6.3 \%)$ projects. Only $7.2 \%$ of respondents indicated that they were affiliated with any state-funded or federally funded genomic health alliances. Figure 2 describes proportions of respondent specialties, compared with the proportions expected from reference data. ${ }^{27}$ The largest group of respondents were physicians, totalling $232(56.7 \%)$ responses. Our sample was representative of most specialties with some exceptions: there were more physicians $(p<0.0001$ and fewer anaesthetists $(p=0.002)$, psychiatrists $(p<0.0001)$ and surgeons $(p=0.0001)$.

\section{Current practice in genomic medicine}

Respondents $(\mathrm{n}=387)$ answered a series of questions about their current practice in genomic medicine. Just over half of respondents had contacted their local genetics service in the last 12 months $(\mathrm{n}=203,52.5 \%)$, although this was relatively infrequent, with one-third of these 203 respondents indicating this was once or twice in the last 12 months (36.6\%). The main reasons for contacting genetics services included: seeking information about a suspected genetic condition (48.0\%), advice on how to refer a patient $(42.6 \%)$ and choosing which genetic or genomic test to order $(38.1 \%)$. Of those who had not contacted clinical genetics, the majority indicated that this was because they had not yet needed advice (73.5\%).

Over half of respondents $(n=208,53.9 \%)$ had engaged in genomic sequencing testing in the last 12 months by either ordering a gene panel or E/GS, or referring a patient to a genetics service for those tests. Nearly a third of respondents $(n=121,31.3 \%)$ had ordered at least one of these tests, with $29.0 \% \quad(\mathrm{n}=112)$ ordering a gene panel and $13.0 \%(\mathrm{n}=50)$ ordering E/GS. When asked about frequency of ordering each test in the previous year, the most common response was once or twice for both gene panels $(\mathrm{n}=42 / 112,37.5 \%)$ and E/GS $(\mathrm{n}=23 / 50,46.0 \%)$. In contrast, 112 respondents $(29.0 \%)$ had ordered a microarray in the previous year, most commonly monthly $(n=41 / 112,36.6 \%)$. Funding for tests varied (online supplemental table S4), with microarray tests often funded by the MBS, gene panel tests by the institute/hospital and E/GS tests by research grants. Overall, $63.3 \%$ of respondents $(n=245 / 387)$ had engaged in genetics/genomics in one or more ways: contacting their genetics service, or ordering or referring for a microarray, gene panel or E/ GS test.

Respondents were asked to reflect on their confidence about genomic concepts and skills (figure 3). Medical specialists reported the highest level of confidence when taking a family history to elicit information about genetic conditions, and lowest for knowledge about genomics. There was greatest variation in their confidence to make decisions based on genomic information $(\mathrm{IQR}=2-7)$.

\section{Current practice compared with expected future practice in genomic medicine}

Overall, two-thirds of respondents think genomics will impact their practice in the next 2 years $(n=199 / 298$, $66.8 \%)$. Of those medical specialists who think their practice will be impacted, they anticipate it will change the way they manage patients $(n=177 / 199,88.9 \%)$ and practice medicine $(n=151 / 199,75.8 \%)$, more so than impact on workload $(n=86 / 199,43.2 \%)$. For respondents who felt genomics would not impact their practice in the next 2 years $(\mathrm{n}=50 / 298,16.8 \%)$, open-text comments $(n=47)$ suggested this was due to perceived relevance to their specialty, timing and/or pragmatic issues of service delivery (see online supplemental table S3). The remaining 49/298 (16.4\%) respondents were 'unsure'. 


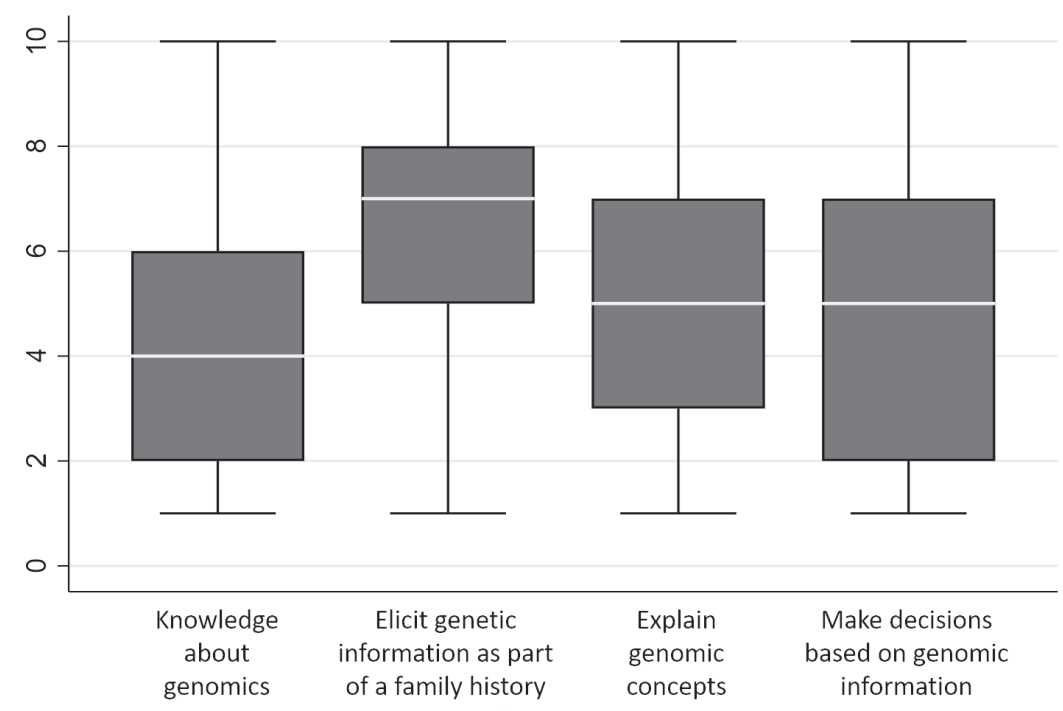

Figure 3 Average confidence about genomic concepts and skills on a scale of 1 'not at all confident', 5 'neutral' to 10 'very confident' ( $n=273)$. Boxes represent the interquartile ranges with minimum and maximum value; medians are shown as white bars.

More respondents currently perform clinical activities before and after E/GS testing (figure $4, \mathrm{n}=314,10.6 \%$ to $80.3 \%$ across these steps) than are involved in non-clinical activities directly related to the test itself $(6.7 \%$ to $17.0 \%)$. Similar patterns were seen in their expectations of the steps they would perform in the future if they had adequate education, training and support: $40.8 \%$ expect to perform all pretest steps and $23.1 \%$ all post-test steps, while $40.3 \%$ do not expect to perform any steps relating to the test itself. Notably, there were significant increases in the proportion of specialists who expect to perform each step in future practice $(p \leq 0.004$ across all steps), with the exception of eliciting phenotypic information about genetic conditions as part of a family or medical history for the purpose of assisting with variant interpretation, which was already high (80.3\% current, $83.4 \%$ future; $\mathrm{p}=0.3$ ).

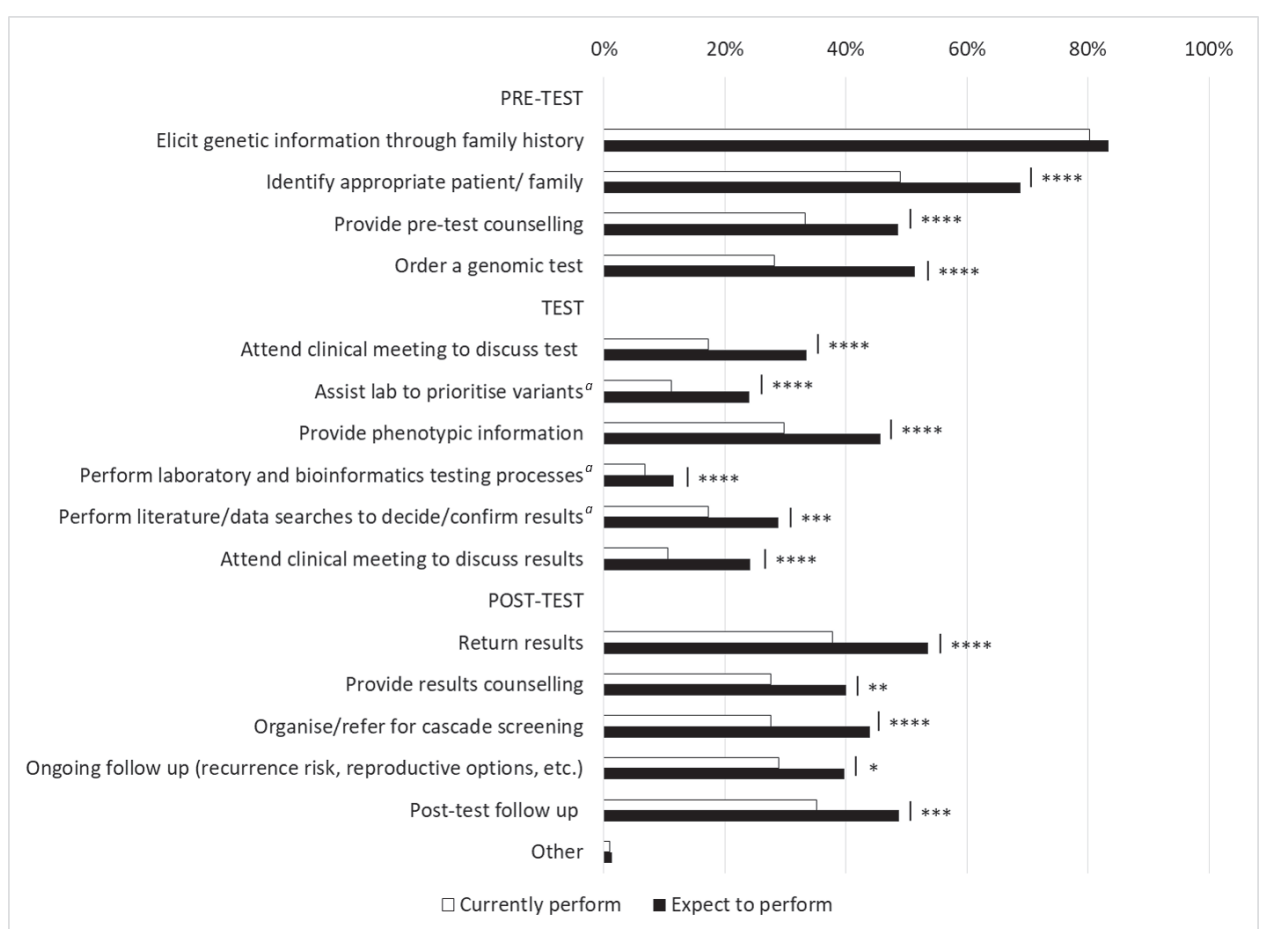

Figure 4 Steps in genomic testing that respondents $(n=314)$ currently perform (white bars) compared with steps they expect to perform in the future, if they had adequate support, education and training (black bars). Non-clinical steps are indicated by ${ }^{a}$. Differences between proportions for 'currently perform' and 'expect to perform' are indicated by ${ }^{\star} \mathrm{p}=0.004$, ${ }^{* \star} \mathrm{p}=0.001$, ${ }^{* \star \star} \mathrm{p}=0.0006,{ }^{* \star \star \star} \mathrm{p}<0.0001$. The difference for the first step - elicit genetic information through family history - was not significant $(p=0.3)$. The full wording of each step is provided in online supplemental table S5. 
Table 2 Medical specialists' preferred models for delivering a genomic sequencing test in inpatient and outpatient settings $(n=218)$

\begin{tabular}{|c|c|c|c|c|}
\hline & \multicolumn{2}{|l|}{$\begin{array}{l}\text { Inpatient } \\
\mathrm{n}=178^{\star}\end{array}$} & \multicolumn{2}{|c|}{$\begin{array}{l}\text { Outpatient } \\
\mathrm{n}=195^{\star}\end{array}$} \\
\hline & $\mathrm{n}(\%)$ & $95 \% \mathrm{Cl}$ & $\mathrm{n}(\%)$ & $95 \% \mathrm{Cl}$ \\
\hline $\begin{array}{l}\text { You initiate testing and discuss results with patients/ } \\
\text { families, with support from a clinical genetics team as } \\
\text { needed }\end{array}$ & $43(24.2)$ & 18.2 to 31.1 & $49(25.1)$ & 19.2 to 31.8 \\
\hline $\begin{array}{l}\text { You refer to a clinical genetics team to initiate testing and } \\
\text { discuss results with patients/families }\end{array}$ & $68(38.2)$ & 31.0 to 45.8 & $87(44.6)$ & 37.5 to 51.9 \\
\hline $\begin{array}{l}\text { You do not see, and do not expect to see, patients who } \\
\text { would benefit from genomic testing }\end{array}$ & $33(18.5)$ & 13.1 to 25.0 & $23(11.8)$ & 7.6 to 17.2 \\
\hline Unsure at this stage & $30(16.9)$ & 11.7 to 23.2 & $28(14.4)$ & 9.8 to 20.1 \\
\hline
\end{tabular}

*A total of 218 respondents completed this question, indicating a preference for either the inpatient or outpatient setting or both.

\section{Preferred future models for delivering genomic medicine}

When reflecting on preferred models for delivering genomic medicine in the future, the model most often selected by respondents was referral to their local genetics services to initiate testing and discuss results (table 2). This was the case for both inpatient and outpatient settings. The second most preferred model was delivering testing with support from a local genetics service. The type of support included: advice on whether testing is appropriate $(60.0 \%$ for inpatients; $66.7 \%$ for outpatients); interpreting results $(72.0 \%$ for inpatients; $75.0 \%$ for outpatients); discussing results with families $(60.0 \%$ for inpatients; $70.8 \%$ for outpatients); or follow-up genetic counselling $(80.0 \%$ for inpatients; $83.3 \%$ for outpatients). A small number expect to initiate genomic testing themselves with no support from a local genetics service, while some respondents also indicated they did not expect to see patients who would benefit from genomic testing. Overall, significantly more respondents preferred a model that includes involvement of genetics services (for support or referral) than a model of initiating testing themselves: inpatients, $62.4 \%$ (95\% CI 54.8\% to $69.5 \%$ ) compared with $2.3 \%$ (95\% CI $0.6 \%$ to $5.6 \%$ ), p $<0.0001$ ); outpatients, $69.7 \%$ (95\% CI $62.8 \%$ to $76.1 \%$ ) compared with $4.1 \%$; (95\% CI $1.8 \%$ to $7.9 \%$, p $<0.0001)$.

\section{Preparedness for genomic medicine and preferences for future education}

While one-third ( $\mathrm{n}=92 / 273,33.7 \%)$ of respondents had completed education in genomics in the past year, only a quarter $(\mathrm{n}=73 / 297,24.6 \%)$ felt prepared to use genomic sequencing testing in their practice. Comments from those who did not feel prepared or were 'unsure' ( $n=210$ combined) primarily suggest this could be addressed through genomics education and training (online supplemental table S3). Forty-two per cent of respondents felt that improved genomic knowledge may alter their clinical practice $(\mathrm{n}=115 / 273,42.1 \%)$ but a similar proportion were 'unsure' ( $\mathrm{n}=114 / 273,41.8 \%)$.

When asked about preferred modes of learning genomics, most respondents $(n=250 / 273 ; 91.6 \%)$ endorsed at least three different modes (table 3 ). The two most commonly preferred-CPD activities and learning from peers-were also the two most commonly used currently. In contrast, reading specialty texts was the third most common way of learning about genomics currently, but the eighth preferred. Respondents indicated a preference for genomics education incorporated into their usual work activities (eg, internal workplace seminars, departmental presentations and clinical meetings).

Despite three-quarters of respondents reporting they had already learnt basic concepts of genomics (table 4; $\mathrm{n}=271$ ), a similar proportion still requested this topic for future education. Six topics were endorsed by over $80 \%$ of respondents including current and emerging applications in genomic medicine, the clinical utility of different tests and topics around patient management. Again, respondents could select more than one topic, with $92.3 \%$ indicating they wanted to learn about at least five topics in the future, and $26.4 \%$ selecting all topics. Nearly two-thirds of respondents indicated they wanted to learn about communication skills with patients, with comments throughout the survey suggesting a need for training in how to explain genomic testing concepts, implications and results to patients.

\section{DISCUSSION}

This paper provides a baseline snapshot of Australian nongenetic medical specialists' practice of genomic medicine and perspectives at a point in time before $\mathrm{E} / \mathrm{GS}$ was widely available to them as a funded clinical test. In $2019,60 \%$ of all 409 survey respondents reported some form of interaction with genetics services or genetic/genomic testing. The test ordered most frequently was a microarray, but 
Table 3 Current and preferred modes of learning about genomics $(n=273)^{\star}$

\begin{tabular}{|c|c|c|}
\hline Mode of learning about genomics & Currently use (\%) & Prefer to use (\%) \\
\hline Continuing professional development/continuing medical education activities & 51.8 & 79.8 \\
\hline Consult colleagues and peer & 54.0 & 79.4 \\
\hline Departmental presentations & 35.8 & 72.0 \\
\hline Clinical meetings & 34.8 & 71.4 \\
\hline Internal workplace genetic or genomic seminars, conferences, etc & 24.9 & 66.3 \\
\hline Reading specialty texts & 48.2 & 63.2 \\
\hline Online webinars, courses, massive open online courses (MOOCs), etc & 15.8 & 59.6 \\
\hline Certification/fellowship activities & 34.4 & 56.4 \\
\hline External genetic or genomic seminars, conferences, etc & 18.4 & 50.0 \\
\hline Genomic research project & 17.6 & 32.6 \\
\hline Time in a service or laboratory with genomics expertise & 6.2 & 17.6 \\
\hline Mass media & 12.5 & 14.0 \\
\hline Social media & 7.4 & 11.0 \\
\hline Other (eg, fact sheet written by geneticist) & 0.0 & 0.4 \\
\hline
\end{tabular}

${ }^{*}$ Respondents could select more than one mode.

more than a quarter of all survey respondents indicated they had ordered a genomic sequencing test in the past 12 months. Respondents anticipated their practice would change in the near future, with significantly more respondents expecting to be involved in activities relating to $\mathrm{E} /$ GS in the next 2 years than currently. Consistent with discipline-specific studies from other countries, ${ }^{13} 15$ 32-34 we found the majority of respondents in our survey did not feel prepared to use genomic sequencing testing in their practice and over two-thirds preferred a model that involved genetics services in some way. Our study extends existing literature by providing greater depth of insight into the education needs and preferences of a broad range of medical specialists.

A strength of this snapshot is the use of a survey tool ${ }^{24}$ grounded in a theoretical model. The COM-B model posits that behaviour is influenced by capability, opportunity and motivation. ${ }^{22}$ Opportunity is clearly impacted by the availability of funded genomic tests. The test usage reported by respondents in this study reflects the availability of MBS reimbursement. For instance, microarrays for developmental delay have been established as MBSreimbursed pathology tests for a decade. Tests reimbursed at the time of this survey are most typically requested by oncologists, clinical geneticists, haematologists, immunologists, paediatricians, obstetricians, nephrologists and neurologists. ${ }^{35}$ Our survey sample included these specialties, barring clinical geneticists and oncologists, who were not the focus of this study. At the time of this survey E/ GS tests were not reimbursed by the MBS. The relatively lower proportion of respondents who had ordered these tests used a variety of other funding mechanisms, most commonly hospital or research funds, and noted availability of funding as an influence when ordering genomic tests in the future. Since this study was completed, MBS now reimburses genomic sequencing tests for some clinical indications when ordered by paediatricians, enhancing their opportunity to use genomic testing in their clinical practice. It is anticipated that reimbursement for other clinical indications (and medical specialties) will follow in the future.

Broadening the responsibility for delivering genomic medicine to non-genetic medical specialties may address issues such as patient access, genetics workforce capacity or long wait times for genetics consultations. However, the medical specialists surveyed in our study show a clear preference for a model of genomic medicine that involves support from genetics services, rather than ordering tests and managing patients themselves. This may relate in part to their capacity to respond, such as constraints on their own time or competing health priorities. However, it is clear that there is a gap in respondents' perceived capability to respond to the availability of funded tests. Currently, respondents lack confidence in their knowledge and ability to explain genomic concepts, and make decisions based on genomic information. This may explain their desire to practice collaboratively with clinical geneticists and genetic counsellors to varying extents. It is possible that these service model preferences could change as their capability (and confidence in their 
Table 4 Topics relevant to genomic medicine that medical specialists have learnt about or would like to learn (more) about $(n=271)^{*}$

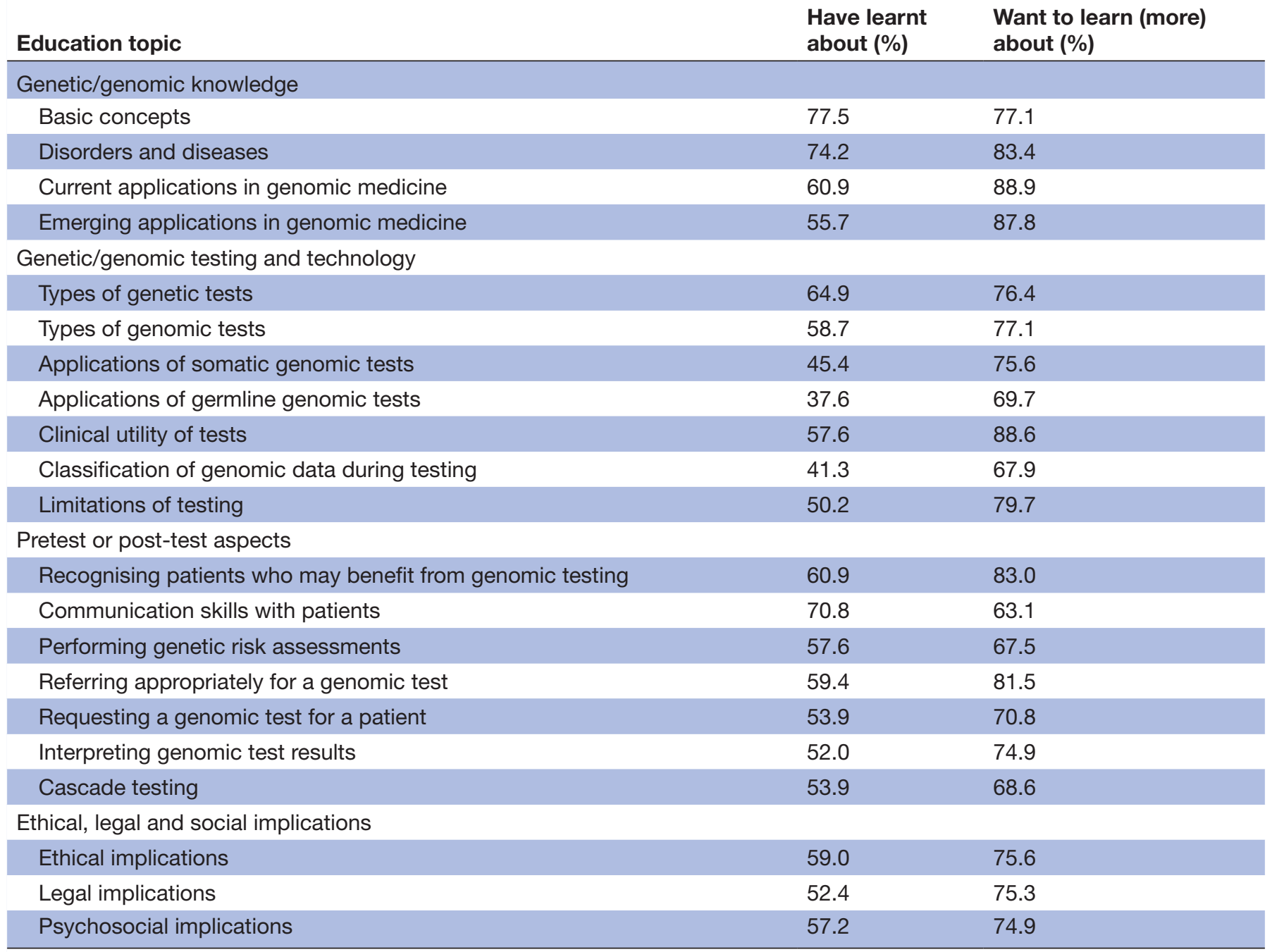

${ }^{*}$ Respondents could select more than one topic.

capability) develops with greater opportunity, experience and learning. ${ }^{22}{ }^{24}$ Education and training was certainly seen as a solution to feeling unprepared by a substantial proportion of respondents in this study, as also observed by others. ${ }^{36}$ In the past 2 years, continuing education for Australian medical specialists has been produced locally at an introductory level by a number of initiatives and organisations (for example, https://elearning.racp.edu. $\mathrm{au} /$ course and http://learn-genomics.org.au/). More is clearly needed: survey respondents are very interested in genomics education and nearly all respondents selected five or more of the topics that they wished to learn about. This is perhaps unsurprising given their perception of being unprepared and expectation of a greater role in the near future, provided they receive adequate support and education. The most popular education topics were related to pretest aspects of testing, such as identifying appropriate patients to refer and knowing how to refer, consistent with the significantly stronger preference for a genetics-led model for genomic medicine. Educational strategies will need to consider both the diversity of respondents' preferences for modes of learning and timing with respect to clinical implementation. Not only will timing affect perceived relevance to clinical practice, and therefore, motivation to learn, ${ }^{37}$ but preferences and needs may evolve as implementation progresses.

Our rigorously developed survey tool can be deployed again in the future to capture changes in workforce practice and preferences over time. It could also be repurposed to inform needs for national education initiatives targeted to specific specialties or to assess change in their knowledge, practice or preferences. Wider use of the tool can also provide a basis for documenting and comparing data across specialties and countries. Our experience with deployment of the survey may assist in this regard, as we purposefully staggered recruitment methods to monitor response rates. Although it is not possible to determine which recruitment approach was most successful because of overlapping timeframes, increases in the number of responses to our survey coincided with recruitment 
approaches using social media, internal hospital communication channels and investigator networks. This may reflect increasing professional use of social media by medical specialists ${ }^{38}$ and greater attention to emails from their employing hospital than a medical college or society. It may also explain the higher representation of Fellows and older specialists in our sample, as trainees were often not on staff mailing lists used by hospitals to distribute the survey. Our staggered and comprehensive recruitment approach also achieved a strong response from rural and remote medical specialists, who are often missed in research. Under-representation or over-representation of medical specialists in some Australian states may be due to differences in governance (hospital and/or research) and site-based communication policies that limited dissemination of the survey. One could assume specialists who graduated more recently may be more engaged with genomic medicine but previous research from our group described varied genomic literacy and experience at each career stage. ${ }^{20}$ Similarly, specialists working in metropolitan areas, where almost all genetics services are based, might have been expected to be likely to complete our survey but this was not seen in our sample. While it is not possible to determine the response rate, our sample represents $1.2 \%$ of 37000 medical specialist registrants with the Medical Board of Australia ${ }^{27}$ and is within the range achieved in similar surveys of American physicians that also recruited participants through medical societies and associations $(0.6 \%-2.6 \%) .{ }^{139-41}$

This national snapshot of medical specialists' current practice in genomic medicine provides the first detailed insight into the continuing genomics education needs of a broad group of subspecialties. It includes some specialties, such as emergency medicine, palliative medicine and infectious disease, for the first time internationally. Those currently involved and/or most interested in genomic medicine may have been more likely to respond, meaning these results may present an overestimation of current practice in Australia, but this might also mean our respondents are those likely to undertake continuing education and engaging with genomics. Consequently, our results can assist educators to best meet learner needs when developing and implementing genomics education to ultimately create a competent, genomics-literate workforce. The findings will also be helpful to genetics services and other clinical services implementing models for genomic medicine delivery. Further data analysis will provide insights into any differences between early adopters of genomic medicine and those who have not yet engaged, enabling the development of targeted, tailored genomics education and other capability-building strategies for optimising the adoption of genomics by medical specialists.

Acknowledgements The authors acknowledge the input and oversight provided by the Australian Genomics Workforce \& Education Working Group. We thank Rigan Tytherleigh for her advice on statistical analyses and Erin Crellin for her assistance in interpretation of the COM-B model and behaviour change framework. We thank all those who helped deploy the survey, including administrative, human resources and communications staff at medical colleges, medical societies, hospitals, and the Australian Genomics and Melbourne Genomics Health Alliances. Colleges, societies and organisations who advertised the survey included the: Australasian College of Dermatologists; Australasian College of Emergency Medicine; Australasian College of Sport \& Exercise Physicians (ACSEP); Australasian Society for Infectious Diseases; Australasian Society for Ultrasound Medicine; Australasian Society of Clinical \& Experimental Pharmacologists \& Toxicologists; Australasian Society of Clinical Immunology \& Allergy; Australia \& New Zealand Child Neurology Society Limited; Australian \& New Zealand College of Anaesthetists (ANZCA); Australian \& New Zealand Hepatic, Pancreatic \& Biliary Association; Australian \& New Zealand Society of Blood Transfusion; Australian \& New Zealand Society of Nephrology; Australian \& New Zealand Society of Occupational Medicine; Australian \& New Zealand Society of Palliative Medicine; Australian Association for Adolescent Health; Australian Medical Association; Australian Paediatric Endocrinology Group; Australian Paediatric Research Network; Australian Paediatric Society; Australian Rheumatology Association; Australian Society of Anaesthetists; Australian Society of Ophthalmologists; College of Intensive Care Medicine of Australia \& New Zealand; Endocrine Society of Australia; Gastroenterological Society of Australia; Royal Australasian College of Physicians; Royal Australasian College of Surgeons; Royal Australian \& New Zealand College of Ophthalmologists; Royal Australian \& New Zealand College of Psychiatrists; Royal Australian College of Obstetricians \& Gynaecologists (RANZCOG); Rural Doctors Association Australia; Society of Obstetric Medicine of Australia \& New Zealand; and Thoracic Society of Australia \& New Zealand. Publication fees were waived by ACSEP and reduced by ANZCA and RANZCOG.

Collaborators Australian Genomics Workforce \& Education Working Group: Kate Dunlop, Debra Graves, Bronwyn Terrill in addition to the authors of this article.

Contributors $A N$ and EAK were involved in all stages of this work and manuscript preparation. BM, SM and CG were involved with all stages except data acquisition. $\mathrm{MJ}$ analysed the qualitative data responses and was involved in manuscript preparation. All authors agree to be accountable for all aspects of the work in ensuring that questions related to the accuracy or integrity of any part of the work are appropriately investigated and resolved.

Funding This work was supported by the Victorian Government's Operational Infrastructure Support Program and a grant from the Australian National Health \& Medical Research Council (NHMRC; GNT1113531); the contents are solely the responsibility of the individual authors and do not reflect the views of the NHMRC

\section{Competing interests None declared.}

Patient consent for publication Not required.

Ethics approval This project received ethics approval from the University of Melbourne, Melbourne, Australia (HREC number: 1646785.10)

Provenance and peer review Not commissioned; externally peer reviewed.

Data availability statement Data are available on reasonable request.

Supplemental material This content has been supplied by the author(s). It has not been vetted by BMJ Publishing Group Limited (BMJ) and may not have been peer-reviewed. Any opinions or recommendations discussed are solely those of the author(s) and are not endorsed by BMJ. BMJ disclaims all liability and responsibility arising from any reliance placed on the content. Where the content includes any translated material, BMJ does not warrant the accuracy and reliability of the translations (including but not limited to local regulations, clinical guidelines, terminology, drug names and drug dosages), and is not responsible for any error and/or omissions arising from translation and adaptation or otherwise.

Open access This is an open access article distributed in accordance with the Creative Commons Attribution Non Commercial (CC BY-NC 4.0) license, which permits others to distribute, remix, adapt, build upon this work non-commercially, and license their derivative works on different terms, provided the original work is properly cited, appropriate credit is given, any changes made indicated, and the use is non-commercial. See: http://creativecommons.org/licenses/by-nc/4.0/.

ORCID iD

Amy Nisselle http://orcid.org/0000-0002-8908-5906

\section{REFERENCES}

1 Birney E, Vamathevan J, Goodhand P. Genomics in healthcare: GA4GH looks to 2022. BioRxiv 2017.

2 Unim B, Pitini E, Lagerberg T, et al. Current genetic service delivery models for the provision of genetic testing in Europe: a systematic review of the literature. Front Genet 2019;10:552. 
3 Maiese DR, Keehn A, Lyon M, et al. Current conditions in medical genetics practice. Genet Med 2019;21:1874-7.

4 Nisselle A, Macciocca I, McKenzie F, et al. Readiness of clinical genetic healthcare professionals to provide genomic medicine: an Australian census. J Genet Couns 2019;28:367-77.

5 Dragojlovic N, Borle K, Kopac N, et al. The composition and capacity of the clinical genetics workforce in high-income countries: a scoping review. Genet Med 2020;22:1437-49.

6 Stark Z, Boughtwood T, Phillips P, et al. Australian genomics: a federated model for integrating genomics into healthcare. Am J Hum Genet 2019;105:7-14.

7 Australian Government Department of Health. Changes to the MBS commencing from 1 May 2020: Australian Government, 2020. Available: http://www.mbsonline.gov.au/internet/mbsonline/ publishing.nsf/Content/20200501-News

8 Stark Z, Nisselle A, McClaren B, et al. Attitudes of Australian health professionals towards rapid genomic testing in neonatal and paediatric intensive care. Eur J Hum Genet 2019;27:1493-501.

9 Johnson L-M, Valdez JM, Quinn EA, et al. Integrating next-generation sequencing into pediatric oncology practice: an assessment of physician confidence and understanding of clinical genomics. Cancer 2017;123:2352-9.

10 White S, Jacobs C, Phillips J. Mainstreaming genetics and genomics: a systematic review of the barriers and facilitators for nurses and physicians in secondary and tertiary care. Genet Med 2020;22:1149-55.

11 van Langen IM, Birnie E, Leschot NJ, et al. Genetic knowledge and counselling skills of Dutch cardiologists: sufficient for the genomics era? Eur Heart J 2003;24:560-6.

12 Nippert I, Harris HJ, Julian-Reynier C, et al. Confidence of primary care physicians in their ability to carry out basic medical genetic tasks-a European survey in five countries-Part 1. J Community Genet 2011;2:1-11.

13 McCauley MP, Marcus RK, Strong KA. Genetics and genomics in clinical practice: the views of Wisconsin physicians. Wisc Med J 2017:116:69-74.

14 Al Bakir I, Sebepos-Rogers GM, Burton H, et al. Mainstreaming of genomic medicine in gastroenterology, present and future: a nationwide survey of UK gastroenterology trainees. BMJ Open 2019;9:e030505.

15 Jaitovich Groisman I, Hurlimann T, Shoham A, et al. Practices and views of neurologists regarding the use of whole-genome sequencing in clinical settings: a web-based survey. Eur J Hum Genet 2017;25:801-8.

16 Talwar D, Tseng T-S, Foster M, et al. Genetics/genomics education for nongenetic health professionals: a systematic literature review. Genet Med 2017;19:725-32.

17 Paneque M, Turchetti D, Jackson L, et al. A systematic review of interventions to provide genetics education for primary care. $B M C$ Fam Pract 2016;17:89.

18 Guttmacher AE, Porteous ME, McInerney JD. Educating healthcare professionals about genetics and genomics. Nat Rev Genet 2007;8:151-7.

19 McGrath S, Ghersi D. Building towards precision medicine: empowering medical professionals for the next revolution. BMC Med Genomics 2016;9:23.

20 McClaren BJ, Crellin E, Janinski M, et al. Preparing medical specialists for genomic medicine: continuing education should include opportunities for experiential learning. Front Genet 2020;11:151.

21 Korf BR, Berry AB, Limson M, et al. Framework for development of physician competencies in genomic medicine: report of the Competencies Working Group of the Inter-Society Coordinating Committee for Physician Education in Genomics. Genet Med 2014;16:804-9.
22 Michie S, van Stralen MM, West R. The behaviour change wheel: a new method for characterising and designing behaviour change interventions. Implement Sci 2011;6:42.

23 Australian Medical Association. Careers: becoming a doctor, 2019. Available: https://ama.com.au/careers/becoming-a-doctor [Accessed $27 \mathrm{Feb}$ 2020].

24 McClaren BJ, King EA, Crellin E, et al. Development of an evidencebased, theory-informed national survey of physician preparedness for genomic medicine and preferences for genomics continuing education. Front Genet 2020;11:59.

25 Harris PA, Taylor R, Thielke R, et al. Research electronic data capture (REDCap)--a metadata-driven methodology and workflow process for providing translational research informatics support. J Biomed Inform 2009;42:377-81.

26 Australian Institute of Health and Welfare. MyHospitals, 2020. Australian Government. Available: https://www.aihw.gov.au/ myhospitals [Accessed Jun 2018].

27 Registration Data Table - June 2019. Australian health practitioner regulation agency, 2019. Medical Board of Australia. Available: https://www.medicalboard.gov.au/News/Statistics.aspx [Accessed 5 May 2020].

28 Australian Government Department of Health. Medical education and training in Australia 1st edition report, 2017. Available: https://hwd health.gov.au/publications.html\#part-2 [Accessed 21 May 2020].

29 Australian Government Department of Health. Health Workforce Data - Medical Education and Training (3rd) report tables, 2018. Australian Government. Available: https://hwd.health.gov.au/met. html [Accessed 21 May 2020].

30 Australian Government Department of Health. Medical workforce 2016 Factsheet, 2017. Australian Government. Available: https:// hwd.health.gov.au/publications.html\#part-2 [Accessed 5 May 2020].

31 healthdirect. Australia's Healthcare System, 2020. Australian Government. Available: https://www.healthdirect.gov.au/australiashealthcare-system [Accessed 5 May 2020].

32 Bonter K, Desjardins C, Currier N, et al. Personalised medicine in Canada: a survey of adoption and practice in oncology, cardiology and family medicine. BMJ Open 2011;1:e000110.

33 Owusu Obeng A, Fei K, Levy KD, et al. Physician-reported benefits and barriers to clinical implementation of genomic medicine: a multi-site IGNITE-network survey. J Pers Med 2018;8. doi:10.3390/ jpm8030024. [Epub ahead of print: 2407 2018].

34 Selkirk CG, Weissman SM, Anderson A, et al. Physicians' preparedness for integration of genomic and pharmacogenetic testing into practice within a major healthcare system. Genet Test Mol Biomarkers 2013;17:219-25.

35 Australian Government Department of Health. Medicare benefits schedule book. ISBN: 978-1-76007-375-3. Publications Number: 12289. Australian Government 2019 http://www.mbsonline.gov.au/

36 Simpson S, Seller A, Bishop M. Using the findings of a national survey to inform the work of England's genomics education programme. Front Genet 2019;10:1265.

37 Knowles M, Elwood $\mathrm{H}$, Swanson $\mathrm{R}$. The adult learner: the definitive classic in adult education and human resource development. 8th ed. New York: Routledge, 2015. ISBN: 978-0-415-73901-6.

38 Ventola CL. Social media and health care professionals: benefits, risks, and best practices. Pharma Therapeut 2014;39:491-520.

39 Stanek EJ, Sanders CL, Taber KAJ, et al. Adoption of pharmacogenomic testing by US physicians: results of a nationwide survey. Clin Pharmacol Ther 2012;91:450-8.

40 Hofman KJ, Tambor ES, Chase GA, et al. Physicians' knowledge of genetics and genetic tests. Acad Med 1993;68:625-32.

41 Haga SB, Burke W, Ginsburg GS, et al. Primary care physicians knowledge of and experience with pharmacogenetic testing. Clin Genet 2012;82:388-94. 